\title{
Spatial, geomorphological, and seasonal variability of CDOM in estuaries of the Florida Coastal Everglades
}

\author{
Nagamitsu Maie ${ }^{1,2}$, Joseph N. Boyer ${ }^{1}$, Chenyong Yang ${ }^{2}$ \& Rudolf Jaffé ${ }^{1,2, *}$ \\ ${ }^{1}$ Southeast Environmental Research Center, Florida International University, University Park, OE-148 Miami, \\ FL 33143, USA \\ ${ }^{2}$ Department of Chemistry \& Biochemistry, Florida International University, OE-148 Miami, FL 33199, USA \\ (*Author for correspondence: E-mail: jaffer@fiu.edu)
}

Key words: dissolved organic carbon (DOC), chromophoric dissolved organic matter (CDOM), estuaries, Everglades, Florida, fluorescence

\begin{abstract}
This paper demonstrates the usefulness of fluorescence techniques for long-term monitoring and assessment of the dynamics (sources, transport and fate) of chromophoric dissolved organic matter (CDOM) in highly compartmentalized estuarine regions with non-point water sources. Water samples were collected monthly from a total of 73 sampling stations in the Florida Coastal Everglades (FCE) estuaries during 2001 and 2002. Spatial and seasonal variability of CDOM characteristics were investigated for geomorphologically distinct sub-regions within Florida Bay (FB), the Ten Thousand Islands (TTI), and Whitewater Bay (WWB). These variations were observed in both quantity and quality of CDOM. TOC concentrations in the FCE estuaries were generally higher during the wet season (June-October), reflecting high freshwater loadings from the Everglades in TTI, and a high primary productivity of marine biomass in FB. Fluorescence parameters suggested that the CDOM in FB is mainly of marine/microbial origin, while for TTI and WWB a terrestrial origin from Everglades marsh plants and mangroves was evident. Variations in CDOM quality seemed mainly controlled by tidal exchange/mixing of Everglades freshwater with Florida Shelf waters, tidally controlled releases of CDOM from fringe mangroves, primary productivity of marine vegetation in FB and diagenetic processes such as photodegradation (particularly for WWB). The source and dynamics of CDOM in these subtropical estuaries is complex and found to be influenced by many factors including hydrology, geomorphology, vegetation cover, landuse and biogeochemical processes. Simple, easy to measure, high sample throughput fluorescence parameters for surface waters can add valuable information on CDOM dynamics to long-term water quality studies which can not be obtained from quantitative determinations alone.
\end{abstract}

\section{Introduction}

Dissolved organic matter (DOM) plays important roles in biogeochemical processes in aquatic environments including elemental cycling, microbial loop energetics and the transport of materials across landscapes (e.g., Hansell \& Carlson, 2002; Findlay \& Sinsabaugh, 2003). Since most of the N $(>90 \%)$ and $\mathrm{P}(\sim 90 \%)$ are in organic form in the oligotrophic subtropical Florida Coastal Everglades (FCE) (Boyer et al., 1997; Boyer, 2006), information on the sources and dynamics of DOM in this ecosystem are crucial for a thorough understanding of the biogeochemical cycling of nutrients.

The estuarine zone of the FCE is composed of distinct regions, characterized by different geomorphology and affected by different biogeochemical 
processes (Fig. 1). Among them is Florida Bay (FB), a wedge-shaped shallow oligotrophic estuary located to the south of the Everglades, the bottom of which is covered with dense seagrass beds (Zieman et al., 1989). Whitewater Bay (WWB) is a semi-enclosed mangrove estuary with a relatively long water residence time, which receives overland freshwater input from the Everglades marshes. The Ten thousand Islands (TTI) region covers the southwest margin of the FCE and are highly compartmentalized by local geomorphology (Jaffé et al., 2004; Boyer, 2006). The sources of both freshwater and nutrients in FCE estuarine areas are difficult to quantify, owing to the non-point source nature of runoff from the Everglades and the dendritic cross channels in the fringe mangrove zones (Jaffé et al., 2004; Boyer, 2006). Furthermore, the combination of multiple DOM sources (freshwater marsh vegetation, mangroves, phytoplankton, seagrass, etc.), and the potential seasonal variability of their relative contributions, along with photochemical and microbial diagenetic processing and complex advective circulation patterns, make the study of DOM dynamics in the FCE particularly challenging using standard schemes of estuarine ecology.

In an attempt to understand the nutrient dynamics in FCE estuaries, Boyer et al. (1997)

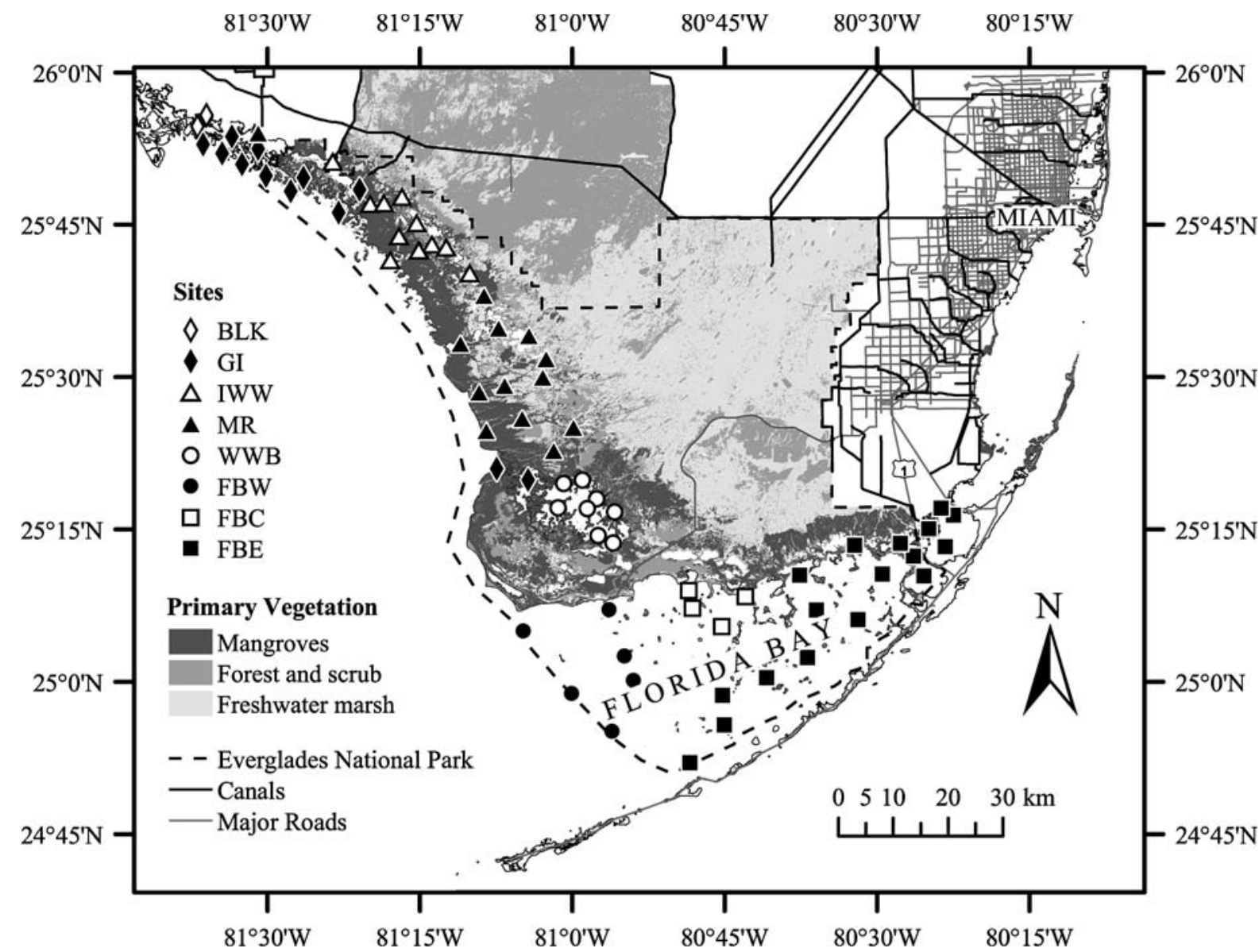

Figure 1. Map of sampling stations in Florida Coastal Everglades estuaries. FB region includes Florida Bay East (FBE; $\mathbf{~ ) , ~ F l o r i d a ~}$ Bay Central (FBC; $\square$ ) and Florida Bay West (FBW; $\bullet$ ). TTI region includes Blackwater River (BLK; $\diamond$ ), Gulf Islands (GI; $\bullet$ ), Inland Waterway (IWW; $\triangle$ ), Mangrove Rivers (MR; $\mathbf{\Delta}$ ). WWB refers to Whitewater Bay $(O)$ ). (Primary vegetation coverage generated by the Center for Remote Sensing and Mapping Science, Department of Geography, The University of Georgia, R. F. Doren, Southeast Regional Office, National Park Service, Florida International University, and K. Rutchey, South Florida Water Management District for Everglades National Park under Cooperative Agreement 5280-4-9006. See also: Jones et al., 1999). 
objectively clustered 27 sampling stations of FB into three zones, namely Florida Bay East (FBE), Florida Bay Central (FBC), and Florida Bay West (FBW), by applying principal component analysis followed by cluster analysis of a 6-years data set of water quality parameters (Fig. 1). In the same manner, based on 10-years of water quality monitoring data, Boyer (2006) also aggregated 46 sampling stations in the TTI/WWB region into 5 distinct clusters. These are the Blackwater River (BLK), Gulf Islands (GI), Inland Waterway (IWW), Mangrove Rivers (MR), and Whitewater Bay (WWB). Marked differences in physical, chemical, and biological characteristics among zones were illustrated by this technique and the observed gradients are believed to be the result of different landuse, freshwater input, geomorphology and sedimentary geology in the region (Boyer et al., 1997; Boyer, 2006).

While water quality parameters such as nutrient levels have been studied in detail in the FCE estuaries (Boyer et al., 1997; Boyer, 2006), less information is available for the DOM, which contains a significant amount of $\mathrm{N}$ and $\mathrm{P}$ in an organic form as mentioned above. In a recent study, Jaffé et al. (2004) studied DOM dynamics in the geomorphological compartmentalized zones of the WWB/TTI region using optical techniques. Based on the data collected from March to May of 1999 and 2001, they showed that the quantity and quality of DOM among zones were controlled by differences in DOM source strength, hydrology, and geomorphology. While quantitative DOM information is very useful to understanding the dynamics and biogeochemical cycling of DOM in estuaries, qualitative data (DOM 'quality') is necessary to better understand the source and biogeochemical processes affecting this DOM.

Fluorescence spectroscopic techniques are very sensitive, relatively simple to perform and provide a large sample throughput. They have been applied to investigate the fate of DOM in numerous estuaries including the Everglades (e.g., Parlanti et al., 2000; Kowalczuk et al., 2003; Stedmon et al., 2003; Alberts et al., 2004; Hitchcock et al., 2004; Jaffé et al., 2004; Yamashita \& Tanoue, 2004; ZanardiLamardo et al., 2004). However, many such studies are performed within a relatively short time frame and do not provide adequate data to assess seasonal variations in DOM sources, transport and fate. In the FCE, seasonality has been suggested as an important variable in DOM dynamics in freshwater marsh environments (Lu et al., 2003). In addition, other water quality parameters also express seasonality in the estuarine zones of the FCE (Boyer et al., 1999). It is expected, therefore, that the source and transport of DOM will be variable as well. This paper is a follow-up to Jaffé et al. (2004), and here the seasonal and geomorphological variation of the fluorescence properties of CDOM is described based on the monthly monitoring of 73 sampling stations in FCE estuaries over nearly two years. Such studies are essential to assess long-term variations in estuarine biogeochemistry as a result of restoration efforts and/or climate change.

\section{Materials and methods}

\section{Site description}

Surface water samples were collected monthly from February 2001 to December 2002 from a total of 73 sampling stations located in the coastal estuaries of the southern tip of the Florida Peninsula, USA. These stations (Fig. 1) were initially established for a long-term water quality monitoring program (http://www.serc.fiu.edu/wqmnetwork; see also Boyer et al., 1997; Boyer, 2006). The sampling stations can be largely grouped into three distinctly different zones based on their geomorphological features: Florida Bay (FB, 27 sampling stations), Ten Thousands Islands (TTI, 38 sampling stations), and Whitewater Bay (WWB, 8 sampling stations). A detailed description of the characteristics of each zone can be found elsewhere (Boyer et al., 1997; Boyer, 2006).

\section{Sample collection}

Samples were collected using pre-washed, brown Nalgen ${ }^{\circledR}$ polyethylene bottles (Nalge Nunc International). Salinity of the water samples was measured in the field using an Orion salinity meter (Thermo Electron, Waltham, MA, USA). The samples were stored on ice and returned to the laboratory. Subsamples for spectroscopic analysis were filtered through pre-combusted $\left(470{ }^{\circ} \mathrm{C}\right.$ for $8 \mathrm{~h})$ Whatman $\mathrm{GF} / \mathrm{F}(<0.7 \mu \mathrm{m})$ glass fiber filters 
once received in the laboratory and analyzed immediately.

\section{Chemical analysis of DOM}

Total organic carbon (TOC) concentration was determined by high-temperature combustion with a Shimadzu TOC-5000A TOC analyzer (Kyoto, Japan). Samples were acidified with $3 \mathrm{M} \mathrm{HCl}$, and purged with $\mathrm{CO}_{2}$-free air to remove inorganic $\mathrm{C}$ prior to analysis. Total $\mathrm{N}$ (TN) was measured on an ANTEK 7000 N Nitrogen Analyzer (Houston, TX, USA) using a previously reported modification to the standard method (Frankovich \& Jones, 1998). Dissolved inorganic N (DIN; nitrate + nitrite $\left(\mathrm{NO}_{x}\right)$, nitrite $\left(\mathrm{NO}_{2}\right)$, and ammonium $\left.\left(\mathrm{NH}_{4}^{+}\right)\right)$ were analyzed on a four channel autoanalyzer (Alpkem model RFA 300, OI Analytical, College Station, TX, USA) and total organic N (TON) was defined as TN-DIN.

\section{Fluorescence emission spectra}

Fluorescence emission spectra were recorded at room temperature $\left(22^{\circ} \mathrm{C}\right)$ using a Perkin Elmer LS50B spectrofluorometer (Wellesley, MA, USA) equipped with a $150-\mathrm{W}$ Xenon arc lamp as the light source. Two fluorescence indices were obtained by single emission scan measurements at excitation wavelengths of 313 and $370 \mathrm{~nm}$. For each scan, fluorescence intensity was measured at emission wavelengths ranging from 330 to $550 \mathrm{~nm}$ and from 385 to $550 \mathrm{~nm}$, respectively, with a $10 \mathrm{~nm}$ bandpass for excitation and emission wavelengths. From the $313 \mathrm{~nm}$ excitation scan the maximum emission intensity $\left(F_{\max }\right)$ and the maximum emission wavelength $\left(\lambda_{\max }\right)$ were determined (Donard et al., 1989; Sierra et al., 1994, 1997). From the $370 \mathrm{~nm}$ excitation scan a fluorescence index (FI), namely the ratio of the fluorescence emission intensities at 450 and $500 \mathrm{~nm}$, was determined (McKnight et al., 2001). Scan speed was set at $400 \mathrm{~nm} \mathrm{~min}^{-1}$. Milli-Q water was used as the blank for all fluorescence analysis. In order to facilitate comparisons with other studies, the $F_{\max }$ was expressed in quinine sulfate units (QSU; $1 \mathrm{QSU}=1 \mathrm{ng}^{-1}$ of quinine sulfate monohydroxide). Synchronous excitation-emission fluorescence spectra of the water samples were obtained at constant offset value between excitation and emission wavelengths $\left(\delta \lambda=\lambda_{\mathrm{em}}-\lambda_{\mathrm{ex}}\right)$. All spectra were recorded at an offset value of $30 \mathrm{~nm}$ with a slit width of $10 \mathrm{~nm}$ (Lu et al., 2003). The intensities of the four main peaks in the spectrum, namely at 275-286 nm (Peak I), $350 \mathrm{~nm}$ (Peak II), $385 \mathrm{~nm}$ (Peak III) and $460 \mathrm{~nm}$ (Peak IV) were determined and the relative intensity of Peak I within this group was reported as \%Peak I. All the fluorescence spectra were corrected for inner-filter effect according to McKnight et al. (2001) using UV-Vis absorption spectra. UV-visible measurements of the water samples were carried out with $1 \mathrm{~cm}$ quartz UV-visible cells at room temperature $\left(22{ }^{\circ} \mathrm{C}\right)$, using a Shimadzu UV-2101PC UV-visible double beam spectrophotometer. Milli-Q water was used as the reference.

\section{Statistical analysis}

Box plots were generated using SigmaPlot 2001 software (SPSS Inc.), where the center horizontal line within the box represents the median of the data, the top and bottom of the box are the 25 th and 75 th percentiles (quartiles), and the ends of the whiskers are the 10th and 90th percentiles. Outliers ( $<10$ th and $>90$ th percentiles) were excluded from the graphs to reduce visual compression. Quantitative and qualitative TOC and DOC variables were grouped into dry (November-May) and wet (June-October) season, and their seasonal and geomorphological variations were analyzed by Student's T-test using JMP 5.0.1 software (SAS Institute Inc).

\section{Results and discussion}

\section{Regional DOM variability}

\section{Quantitative parameters}

Salinity exhibits a clear seasonality for the three distinct regions of TTI, WWB and FB (Fig. 2), increasing during the dry season and decreasing rapidly at the onset of the wet season. The salinity decreased more gradually during the 2001 wet season than for 2002, indicating that the latter year had a larger freshwater input to the estuaries during the early wet season. The mean salinity was highest in FB followed by TTI and WWB (Table 1). Factors affecting salinity include rain- 

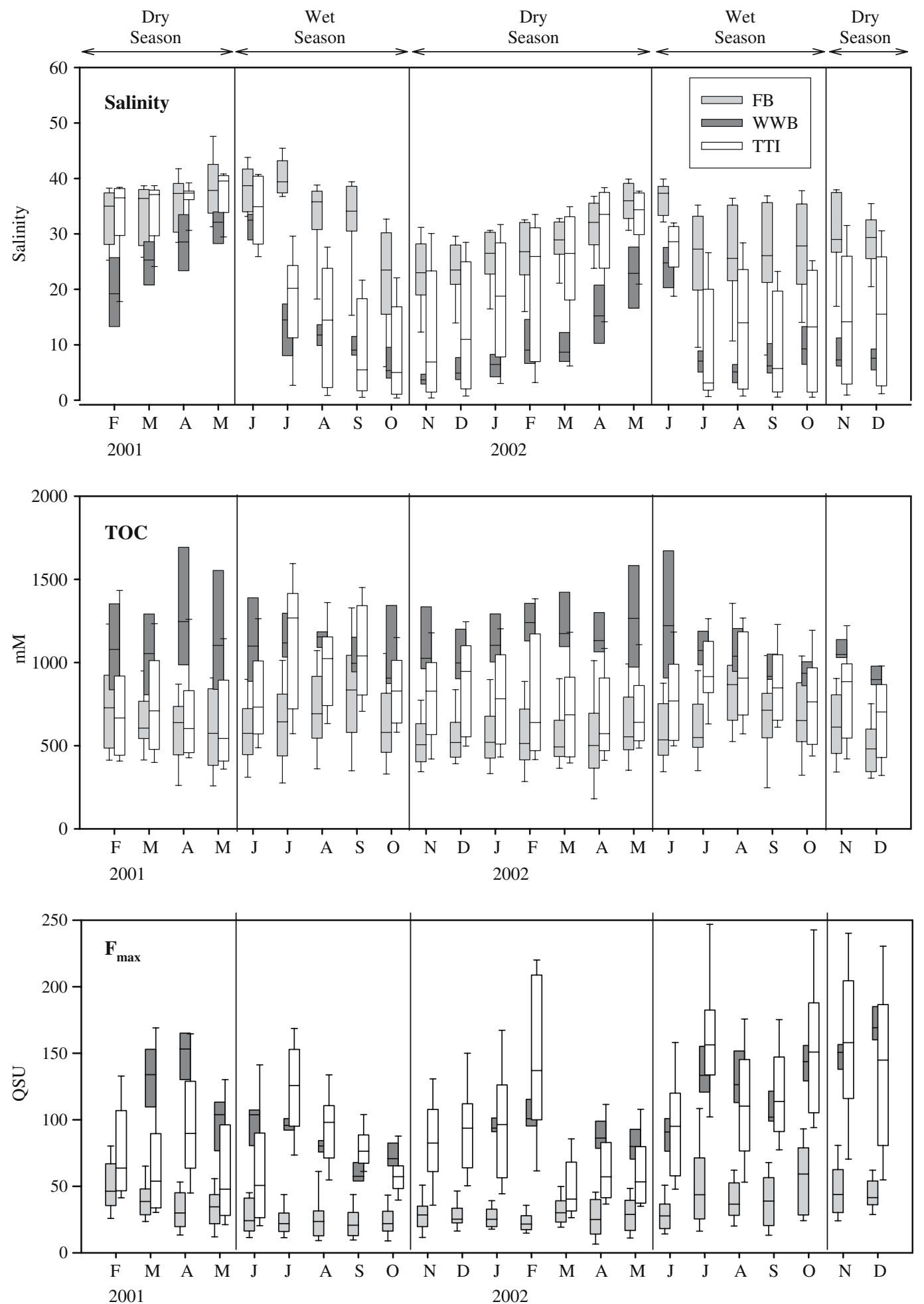

Figure 2. Spatial and seasonal variability of salinity, total organic carbon (TOC) concentration, and maximum fluorescence intensity $\left(F_{\text {max }}\right)$ for geomorphologically distinct zones in the Florida Coastal Everglades estuaries. 


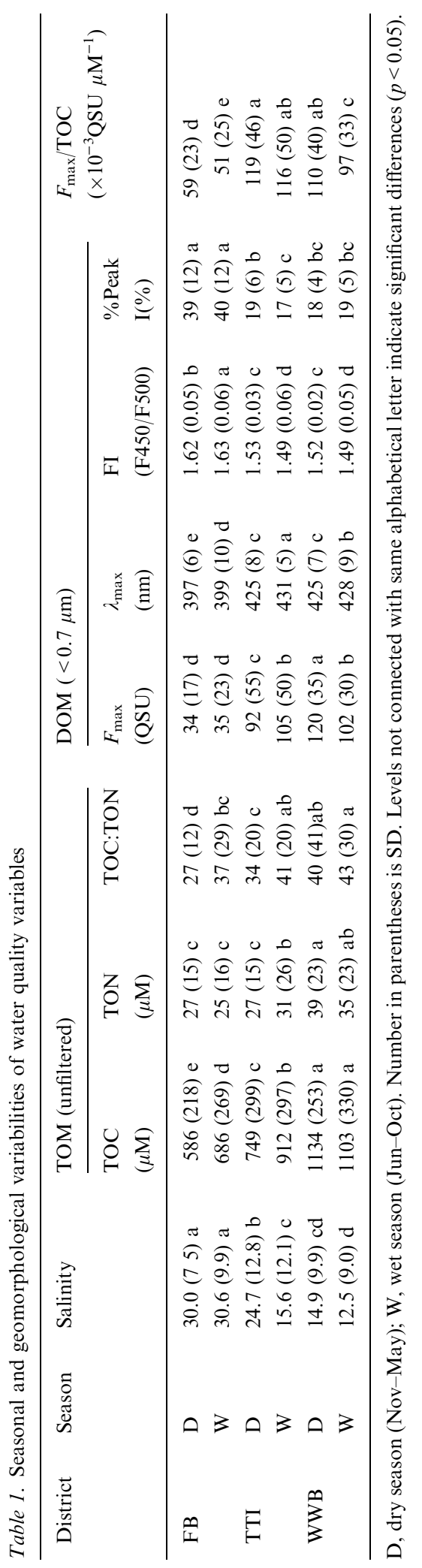


fall, freshwater inputs from the Everglades, tidal mixing with Florida Shelf waters, and concentration by evaporation. The higher salinity in FB suggests that the effect of freshwater inputs from the Everglades is generally lowest for this region and with low tidal exchange, evaporation concentrates water in some portion of the FB. Indeed, its contribution to the total freshwater input to FB was estimated to be only about $\sim 10 \%$ (Nuttle et al., 2000), with the rest being derived from rainfall. Both $\mathrm{FB}$ and $\mathrm{WWB}$ are semi-enclosed systems, where water exchange with the Florida Shelf is limited. Thus, the tidal exchanges of water and resulting salinity shifts are generally smaller than for TTI (Table 1). In contrast, the TTI sites experience active tidal exchange with the Florida Shelf, resulting in the highest seasonal variability in salinity and on short time scales.

Mean TOC concentrations were highest in WWB followed by TTI and lowest in FB (Fig. 2; Table 1). TOC was slightly higher during the wet season for FB and TTI, showing an increase of 100 and $163 \mu \mathrm{M}$, respectively (Table 1; Fig. 2). Although the mean TOC concentration was not significantly different between the dry and wet seasons for WWB (Table 1), the highest TOC and largest range were observed during the dry to wet season transition periods (Fig. 2). While a strong negative correlation between salinity and TOC was observed for TTI $\left(r^{2}=0.45, n=869, p<0.0001\right)$, only a very weak correlation was observed for FB $\left(r^{2}=0.03, n=613, p<0.0001\right)$. As such, the TOC increase during the wet season could be attributed to higher loadings of freshwater-derived terrestrial TOC in the TTI region. The weak correlation for FB suggests that Everglades DOM inputs (including mangrove sources) have only minor influence on the seasonal variability of TOC. Instead, other factors, such as higher primary productivity of seagrass/periphyton community during the wet season as has been observed in south Florida (Fourqurean et al., 2001), seem more important for FB. This explanation is further supported by the qualitative aspect of DOM as will be shown below.

Mean TON concentrations ranged from 25 to $39 \mu \mathrm{M}$ with the highest value for WWB (Table 1). These values are within the range of river systems $(34.7 \pm 20.7)$ and estuaries $(22.5 \pm 17.3)$ elsewhere (Bronk, 2002). Mean C:N ratios of FCE estuaries $(27-43)$ are also within the range observed for a variety of waters $(25.7 \pm 12.5$ and $21.1 \pm 14.3$ for rivers and estuaries, respectively; Bronk, 2002), but tend to be on the higher side. The $\mathrm{C}: \mathrm{N}$ ratio was higher during the wet season for FB and TTI (Table 1). DOM with different $\mathrm{C}: \mathrm{N}$ ratios reflect different DOM sources and/or diagenetic processing (e.g., DOM originating from higher plants has greater $\mathrm{C}: \mathrm{N}$ values than DOM from microbes; Caraco \& Cole, 2003; McKnight et al., 2003). A high $\mathrm{C}: \mathrm{N}$ ratio during the wet season in the $\mathrm{FCE}$ estuaries may be due to a large contribution of DOM freshly leached from senescent plant biomass (Maie et al., 2006).

The maximum fluorescence intensity $\left(F_{\max }\right)$ is often correlated with TOC concentration particularly for coastal environments that are strongly influenced by river inputs (Blough \& Vecchio, 2002). In coastal environments, however, since the $\mathrm{C}$ specific $F_{\max }$ intensity $\left(F_{\max } /\right.$ TOC) can vary depending on the DOM composition, caution needs to be exercised with interpreting $F_{\max }$ data. On the other hand, $F_{\max }$ /TOC provides compositional information of DOM and provide a parameter that is more comparable among different locations. Mean $F_{\max }$ values were higher in TTI and WWB than FB (Table 1). TTI showed a statistically higher $F_{\max }$ during the wet season, while $F_{\max }$ for WWB was highest during the dry season. No seasonal difference in the $F_{\max }$ was observed for FB (Table 1). $F_{\text {max }} /$ TOC was higher for TTI and WWB than for $\mathrm{FB}$, suggesting that the DOM in TTI and WWB is of more terrestrial origin. These values were comparable to those of other studies in the FCE (Clark et al., 2002; Jaffé et al., 2004). In the FCE estuaries, correlations between $F_{\max }$ and TOC were observed for FB and TTI $\left(r^{2}=0.323, p<0.0001, n=594\right.$ for $\mathrm{FB} ; r^{2}=0.432, p<0.0001, n=781$ for TTI), suggesting one of the reasons for the variability in $F_{\max }$ can be explained by the variation of TOC for FB and TTI. However, no correlation for WWB requires a different explanation. WWB is surrounded by mangrove forests, and a large amount of input of CDOM with a terrestrial signature is therefore expected. In addition, WWB is a semi-enclosed system and the water residence time is long. As such, CDOM in the shallow waters of WWB may undergo significant photodegradation. Since photoexposure of DOM was found to decrease the $F_{\max }$ value significantly without a significant change of TOC concentration (Boyer et al., unpublished), DOM 
with different photodegradation histories may result in different carbon specific $F_{\max }$ values. As such, lower $F_{\max }$ and $F_{\max } /$ TOC during the wet season may reflect a more extensive photodegradation history under the stronger and longer light conditions in place during the summer at WWB.

\section{Qualitative parameters}

The maximum emission wavelength $\left(\lambda_{\max }\right)$, the emission wavelength which provides $F_{\max }$, and fluorescence index (FI) have been used to assess the sources of CDOM in the FCE estuaries (Jaffé et al., 2004; Clark et al., 2002). Terrestrial, higher plant-derived DOM typically has lower FI values and longer $\lambda_{\max }$ than marine (microbial and seagrass community) derived DOM (Donard et al., 1989; Battin, 1998; McKnight et al., 2001; unpublished data of authors). In this regard, TTI and WWB showed a longer mean $\lambda_{\max }(\sim 425$ to $431 \mathrm{~nm}$ ) than FB (397-399 nm) (Fig. 3; Table 1), suggesting that the CDOM in FB is not substantially derived from the freshwater marshes or the fringe mangroves in the Everglades, but instead probably produced in FB directly or indirectly by seagrass/phytoplankton community. This interpretation is in agreement with previous reports (Maie et al., 2005; Maie et al., 2006) and further supported by the $\delta^{13} \mathrm{C}$ value of high molecular weight fraction of DOM collected from the FB, which is significantly heavier $(\sim-14 \%)$ than that from the Everglades $(\sim-27 \%$ ) (Maie, personal communication). The longer $\lambda_{\max }$ values for all regions during the wet season compared to the dry season suggest a higher input of terrestrial DOM from the Everglades during wet season. The range of $\lambda_{\max }$ was wider during the wet season for $\mathrm{FB}$, while this was the case during the dry-to-wet transition for TTI and WWB (Fig. 3). A higher loading of Everglades derived terrestrial CDOM to some sampling stations during the wet season is considered to be the reason for this observation in FB, while TTI sites are more strongly influenced by tidal exchange with the Florida Shelf waters during the end of dry season when the freshwater input from the Everglades is at a minimum. For WWB the DOM dynamics during this transition are somewhat puzzling. While the TOC and the salinity remain high, $\lambda_{\max }$ declines in some areas suggesting a short-lived change in DOM source in WWB during this period and implies a larger microbial input not associated with marine waters. Possibly, a pulsed nutrient supply from surrounding mangrove marsh associated with rain events in the early wet season results in increased microbial activity for WWB, however the exact reasons for this observation remain unclear.

The mean FI value was higher in FB (1.62-1.63) than for TTI and WWB (1.49-1.53), supporting the suggestion that the DOM in FB has a different and more marine origin than in the other regions. Seasonal changes in the FI were apparent for WWB and TTI during 2001 where the lowest values were obtained during the wet season, while this was less obvious during 2002 (Fig. 3; Table 1). This may be the result of differences in rainfall and/or the hydrologic regimes between the 2 years, as the salinity decreased more gradually during 2001 than during 2002 (Fig. 2). Both $\lambda_{\max }$ and FI values suggest that $\mathrm{CDOM}$ is more terrestrial in nature during the wet season for TTI and WWB, while these variables showed no consistent trend for FB. This may be due to the difference in the sensitivity of $\lambda_{\max }$ and FI for CDOM with different origin (Fig. 3; Table 1). The $\lambda_{\max }$ shifts to short wavelength (so called blue shifts) $\sim 30 \mathrm{~nm}$ when the dominant DOM source changes from terrestrial to marine (de Souza Sierra et al., 1997) As such, this variable is very useful in detecting the dominant source of DOM in coastal and estuarine environments. In contrast, the FI is less sensitive to such source changes but provides a wider operational range from about 1.3-1.8. The combined use of these complementary parameters can contribute to a more comprehensive understanding of CDOM dynamics. For example, these optical variables suggest that the seasonal variability observed for FB may be due to a higher primary productivity in $\mathrm{FB}$ in addition to a higher CDOM input from the Everglades during wet season (Table 1).

The \%peak I has been used as a proxy for estimating the relative abundance of proteinaceous materials in CDOM ( $\mathrm{Lu}$ et al., 2003; Jaffé et al., 2004) and is used to discriminate between marine and terrestrial DOM sources in estuaries (Sierra et al., 1994). Peak I was generally higher for FB than TTI and WWB in agreement with others (Maie et al., 2006b). The mean \%peak I values were not significantly different by season for FB and WWB, although it was statistically higher during the dry season for TTI, reflecting a more 

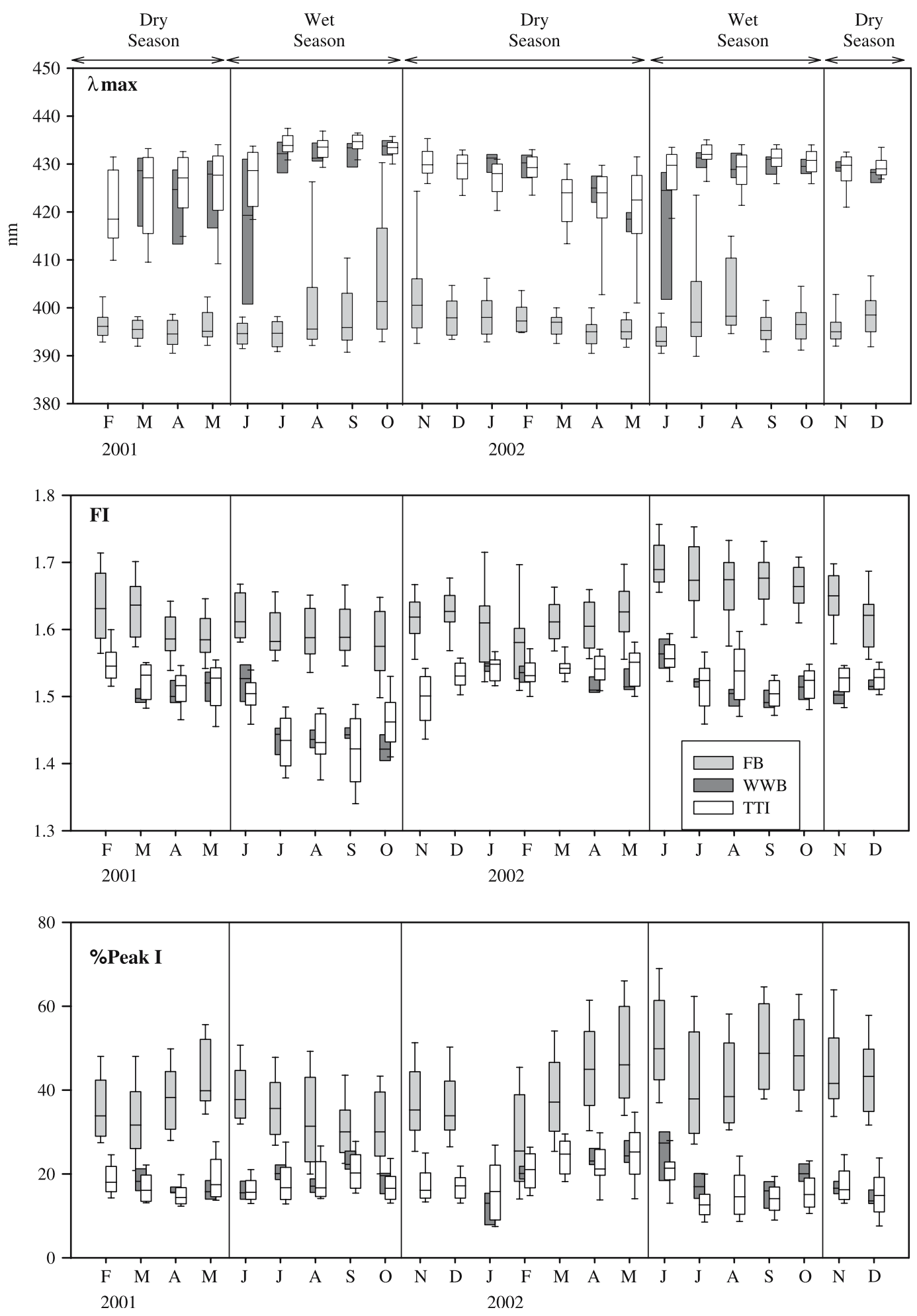

Figure 3. Spatial and seasonal variability of qualitative DOM variables (maximum wavelength $\left(\lambda_{\max }\right)$, Florescence Index (FI), and \%peak I) in geomorphologically distinct zones in the Florida Coastal Everglades estuaries. 
marine nature of the DOM (Fig. 3; Table 1). Although most of the high molecular weight fraction of the DON in the Everglades is in the form of proteinaceous materials (Maie et al. 2006b), the correlation between the \%peak I and the DON:DOC ratio was surprisingly low for all the regions $\left(r^{2}<0.1\right)$, confirming the suggestion by others, that the use of peak I as a proxy for proteinaceous materials has serious limitations (Ferrari \& Mingazzini, 1995; Yamashita \& Tanoue, 2003; N. Maie et al., 2006). Therefore although \%peak I can be useful to distinguish terrestrial from marine DOM, it may be difficult to apply this parameter as a proxy for the relative concentration of proteinaceous materials.

\section{DOM dynamics within previously established water quality zones}

The investigation of three distinct regions of the FCE estuaries revealed that the quantity and quality of DOM was influenced by geomorphological features and seasonality. However, the wide range of deviation in some parameters demonstrates that the biogeochemical cycling of DOM is highly variable within each region and may contain several sub-regions with distinct DOM dynamics. As such, further compartmentalization was necessary to better understand the underlying biogeochemical processes in each system. In the following section, FB and the TTI/WWB regions were subdivided into a total of eight sub-regions or zones (see Fig. 1) according to Boyer et al. (1997) and Boyer (2006), and a more detailed investigation was conducted.

\section{Florida Bay}

An increasing gradient in the salinity was observed from east to west in Florida Bay (Table 2; Fig. 4). TOC was highest in FBC, which was about 1.7 and 2.1 times higher compared to FBE and FBW, respectively (Table 2). TOC was higher for the wet (vs. dry) season in FBE and FBC, but showed no significant seasonal differences for FBW where is least impacted by freshwater loadings from the Everglades. Higher TOC in FBE during the wet season may be due to the large freshwater input from the Everglades, as a significant negative regression between TOC and salinity in the FBE zone $\left(p<0.0001 ; r^{2}=0.09 ; n=385\right)$ was observed.
However, since the dependent variable only accounted for $9 \%$ of the variability, other than terrestrial DOM, such as nutrient loadings, which increase primary productivity, may contribute to this TOC increase. The importance of autochthonous DOM is suggested from consistently shorter $\lambda_{\max }$ values during both the wet and dry seasons (Table 2; Fig. 4). The $\lambda_{\max }$ value also suggested that the CDOM with a terrestrial signature was limited to coastal areas where the salinity is less than 24, or where Everglades fresh water is diluted with estuarine end-member water (at a salinity of 36) by a factor of at most 3 (Fig. 5). The inflection point depends on the DOC concentration of freshwater and marine water, and in open coastal systems, blue shift of $\lambda_{\max }$ is usually observed at salinity higher than 30 (Fig. 7; also see de Souza Sierra et al., 1997; Kowalczuk et al., 2003; Jaffé et al. 2004). The blue shift in lower salinity indicates FB contains a high concentration of DOC with marine origin. At higher salinities, $\lambda_{\max }$ values typical for autochthonous/marine DOM predominated regardless of season.

No significant regression between salinity and TOC was observed in FBC, and as such the high TOC levels in FBC are probably not due to the input of Everglades-derived terrestrial TOC. The optical properties of DOM, the $\lambda_{\max }$ and FI values, showed that DOM in FBC has a more microbial/marine signature compared to terrestrial Everglades'-derived DOM (e.g., MR; Table 2; Fig. 4). Therefore, higher TOC in FBC during the wet season may be due to higher production rates of seagrass/phytoplankton community-derived DOM associated with a higher primary productivity of seagrass (Fourqurean et al., 2001) and evaporative concentration of DOM.

For FBW, no significant regression between the salinity and TOC was observed. Indeed, this zone is least influenced by inflow of Everglades derived fresh water, demonstrated by having the highest salinity of all the study areas. FBW is open to the Florida Shelf and therefore most influenced by tidal exchange with marine waters in $\mathrm{FB}$, resulting in low TOC values. Water drained from MR and its associated DOM may however, reach the FBW zone, since the lowest FI values in FB were observed for this zone during the dry season. This result was surprising since freshwater loading from Shark River Slough that flows through MR zone 


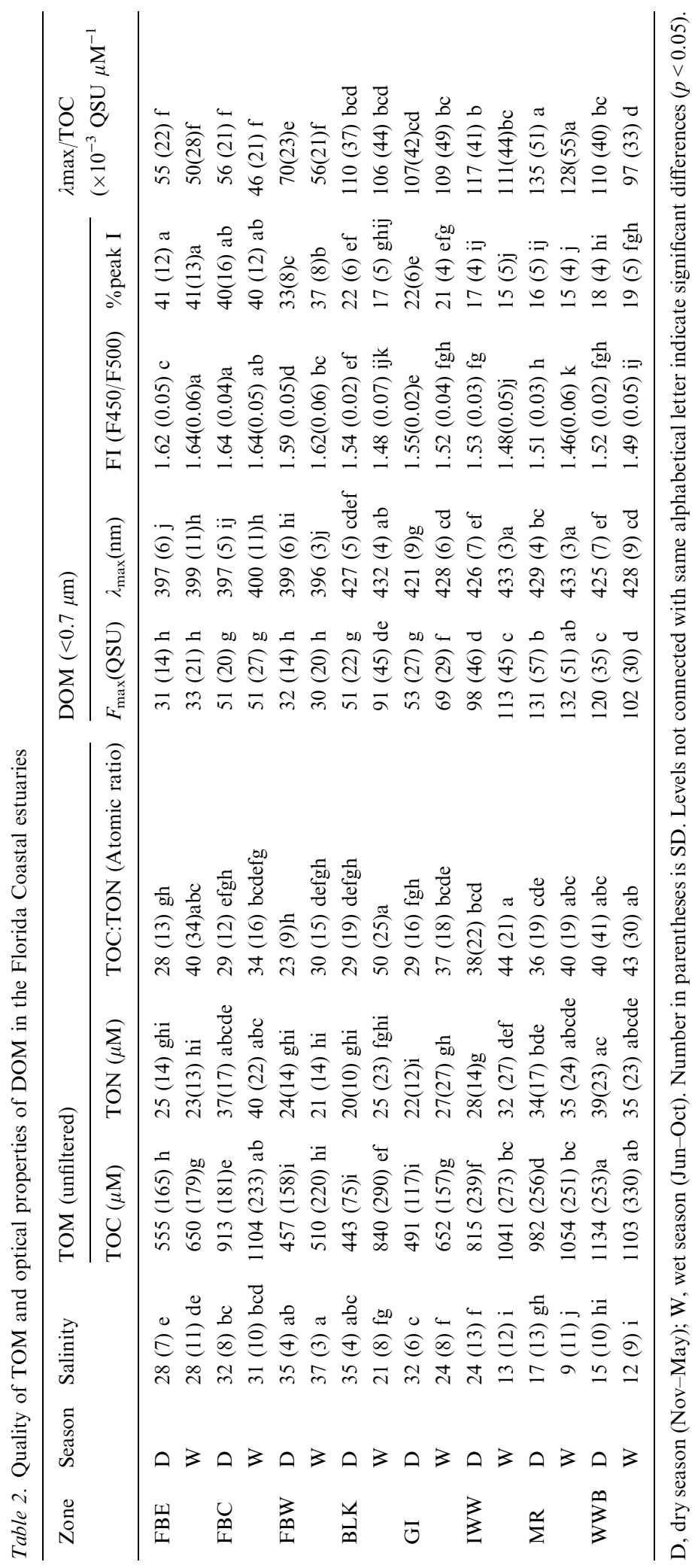



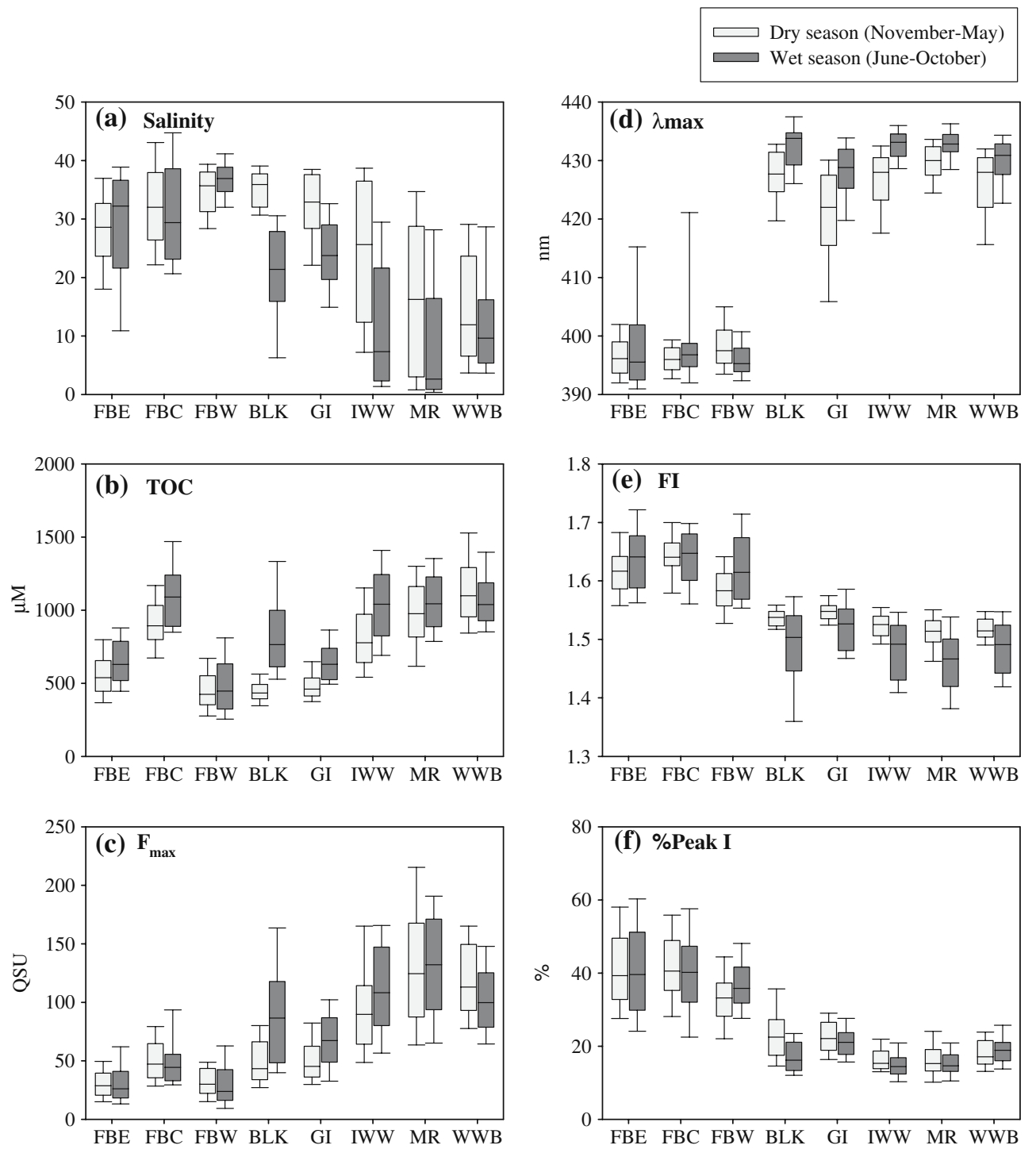

Figure 4. Box plots of water quality variables: (a) salinity; (b) total organic carbon (TOC); (c) maximum fluorescence intensity $\left(F_{\max }\right)$; (d) maximum wavelength $\left(\lambda_{\max }\right)$; (e) fluorescence index (FI); (f) \%Peak I.

to Gulf of Mexico is larger during wet season. However, since optical properties of DOM are controlled by the relative source strength, a higher primary productivity of seagrass/periphyton community during wet season might induce more marine signature to DOM.

\section{Ten Thousand Islands and Whitewater Bay}

The TTI and WWB regions were subdivided into 5 zones as described above, and showed a descending gradient in the salinity from BLK and
GI $>$ IWW $\geq W W B \geq M R$ (Table 2; Fig. 4). Salinity was higher by 3-14 psu during the dry season, reflecting a larger freshwater loading from the Everglades during the wet season. TOC was highest in WWB and lowest in the GI (WWB $\geq \mathrm{MR} \geq \mathrm{IWW}>\mathrm{BLK} \geq \mathrm{GI}$ ). Since all of these sub-regions, with the exception of WWB, had a negative regression between TOC and salinity (Fig. 6), conservative mixing of TOC with Florida Shelf water is considered to be the main reason for the observed variability in TOC (see 


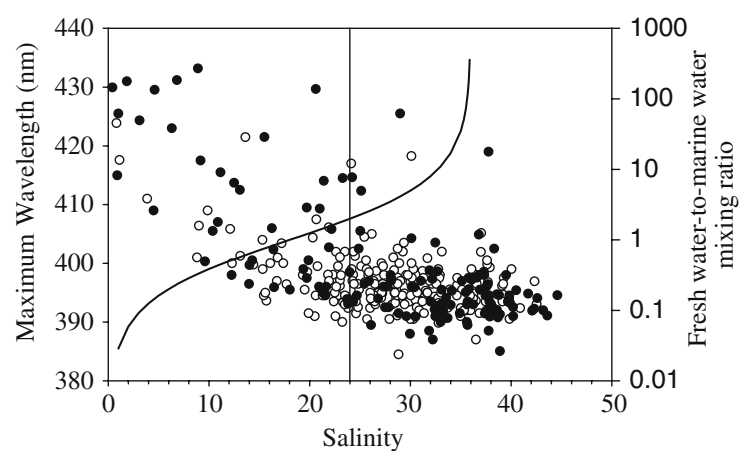

Figure 5. Plots of salinity versus maximum wavelength $\left(\lambda_{\max }\right)$ for water samples in the FBE zone. Open circle=dry season (November-May); closed circle $=$ wet season (June-October). $\lambda_{\max }$ is the emission wavelength that gives two maximum emission intensity with an excitation at $313 \mathrm{~nm}$. Curve of dilution rate of terrestrial end-member (salinity 0 ) with marine end-member (salinity 36 ) is superimposed on the data.

also Cauwet, 2002). However, the slope of the regression lines and the correlation coefficients between salinity and TOC were different among the sub-regions with MR showing the smallest slope, GI and IWW intermediate values and BLK the highest value (Fig. 6). The higher variability and low regression coefficient between salinity and TOC for MR is likely due to seasonal salinity fluctuation in addition to the non-point source nature of DOM in this zone; i.e. the mangrove forest works as a TOC source along the whole river. The importance of mangrove forests as a source of DOC has often been suggested by other researchers (Lee, 1995; Guo et al., 1999; Dittmar et al., 2001; Jaffé et al., 2004). Furthermore, TOC concentration of marine end-member is not independent due to complex advective circulation. Using a simple mixing model, the extrapolation of TOC out to the salinity end-member of 36 was estimated to be $419,471,712$, and $815 \mu \mathrm{M}$, for BLK, GI, IWW, and MR, respectively (Fig. 6). The higher TOC contributions calculated for IWW and MR suggest a higher input of mangrove derived DOM to these zones.

Plots of $\lambda_{\max }$ versus salinity showed inflection points at salinities above 30-35 (Fig. 7; Jaffé et al., 2004). The inflection point appears when the concentration of terrestrial-derived DOM becomes

Figure 6. Plots of salinity versus TOC concentration for the TTI subregions.
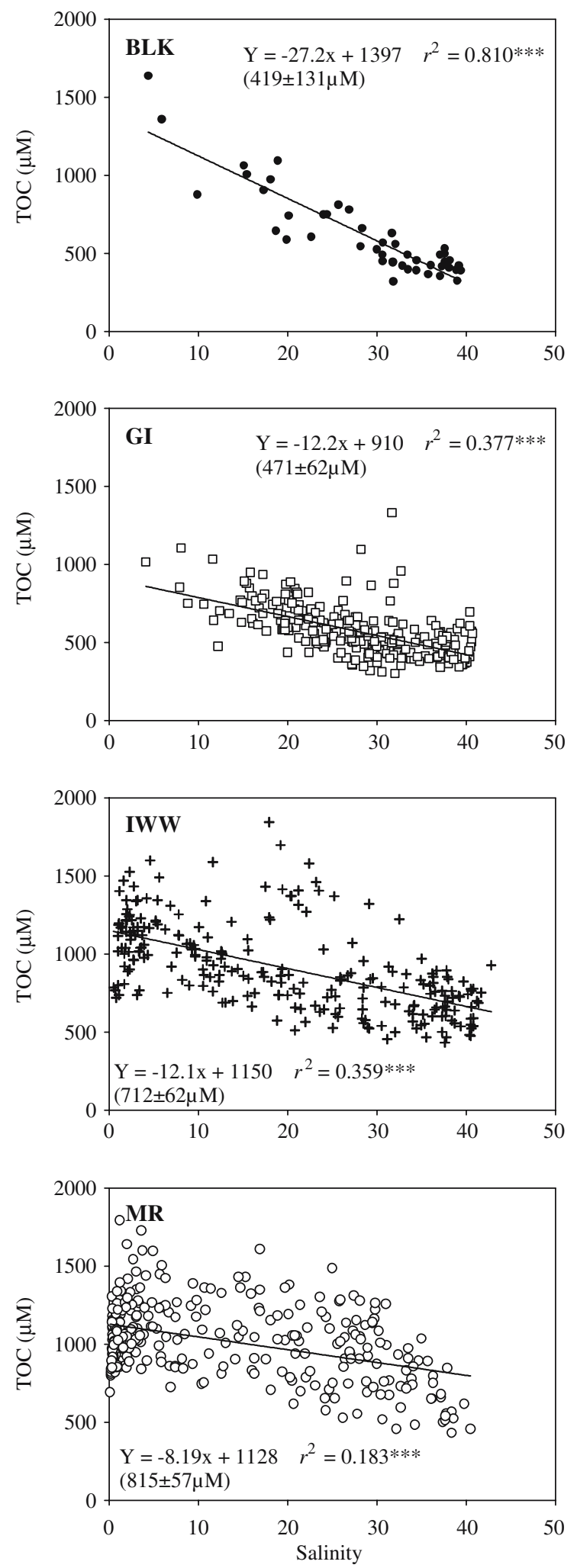

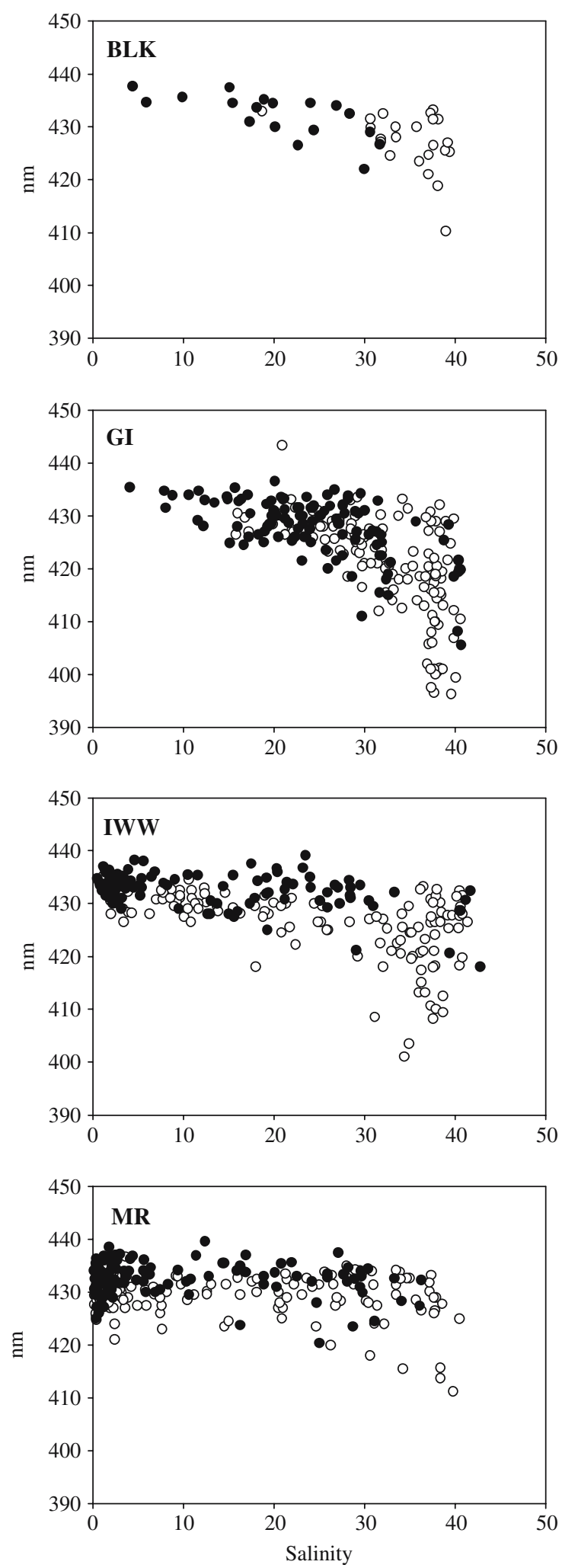

Figure 7 . Plots of salinity versus maximum wavelength $\left(\lambda_{\max }\right)$ for the TTI subregions. $\lambda_{\max }$ is the emission wavelength that gives maximum emission intensity with an excitation at $313 \mathrm{~nm}$. Open circle, dry season (November-May); closed circle, wet season (June-October).

comparable to marine-derived DOM (e.g., de Souza Sierra et al., 1997; Kowalczuk et al., 2003). In this study such 'blue shifts' were mostly observed for the water samples collected during the dry season when the loading of terrestrial DOM was lower. This effect was not observed for the MR sites since the terrestrial DOM loading was greater than the marine-derived DOM. The GI sub-regions showed a wider range of $\lambda_{\max }$ values than IWW and MR at a salinity of about 30 (Fig. 7), indicating a rather simple DOM mixing regime with the marine end-member. compared with IWW and MR where a considerable amount of mangrove derived DOM is washed out by tidal saline waters.

Dry versus wet season variability of the TOC concentration was largest in BLK $>$ IWW $>$ GI $>$ MR $>$ WWB, suggesting that the variation in the loading of TOC from freshwater marshes and mangrove forests is variable among sub-regions and between seasons. For all the TTI/WWB subregions the $\lambda_{\max }$ was longer and the FI was lower during the wet season (Table 2) indicative of higher terrestrial DOM loadings during this time of higher freshwater discharge, implying a hydrological control on DOM quality. This quality was also found to be different among season and/or sub-regions. For example, BLK (wet season) has a similar salinity and TOC concentration to IWW (dry season), but BLK showed a more terrestrial signature (long $\lambda_{\max }$ and short FI) than IWW (see Table 2). The variations in these optical properties are considered to be the result of different mixing ratios of two fluorophores; one with a shorter wavelength that is microbial and one with a longer wavelength that is terrestrial (de Souza Sierra et al., 1997; Parlanti et al., 2000). As such, $\lambda_{\max }$ values are controlled by several possible terrestrial (higher plant) and microbial sources, which depend on water quality, geomorphology, landuse, and hydrology. In BLK a higher contribution of terrestrial DOM may be derived from within the highly agricultural watershed versus the freshwater marsh watershed of the IWW. 


\section{Conclusions}

This study presented the spatial and seasonal variations of DOM quantity and quality in FCE estuaries, reflecting different biogeochemical processes. Since the FCE estuaries are highly compartmentalized and have multiple non-point DOM sources (freshwater marsh, mangrove forest, seagrass/phytoplankton community), finding factors that regulate DOM biogeochemical processes in these environments is a challenge. However, a combination of fluorescence-based analyses of DOM with objective compartmentalization of sampling grid based on other water quality parameters has proven to be a useful technique to better understand DOM dynamics in this complex ecosystem. DOM sources and dynamics are quite different for FB compared to WWB and the TTI due to a large contribution of DOM derived from seagrass/phytoplankton community and relatively small contributions from Everglades freshwater and mangrove sources to the FB. WWB and TTI also showed some significant differences which seem mainly controlled by water exchange rates with the Florida Shelf as well as water residence time and associated photodecomposition processes which seem to affect the WWB DOM in particular. Mangrove forests are important non-point source of DOM in estuarine. Seasonal variations in the FCE estuaries seem to be mainly controlled by hydrology (i.e. transport processes and water exchange), primary productivity variations (i.e., seagrass/phytoplankton community in FB) and sunlight exposure (wet season for WWB). Due to the importance of organic nutrients (DON and DOP) in fueling the microbial loop and controlling primary productivity in the $\mathrm{FCE}$, it is essential to better understand the sources, bioavailability, photodegradability, transport processes and seasonal dynamics of DOM in this ecosystem. For that purpose, investigation of the DOM composition based on the optical properties is the first step, since the reactivity and functionality of DOM depend on its chemical characteristics. With that in mind, further studies are needed to better associate optical properties to source, bioavailability, and photodegradability of DOM. As the Everglades ecosystem undergoes the worlds largest wetland restoration project, monitoring long-term DOM quality will be useful to determine environmental variations and assess potential ecological changes, not only throughout the implementation of Everglades restoration, but also documenting changes induced by climate change and natural disturbances, particularly hurricanes.

\section{Acknowledgements}

This research was funded by the National Science Foundation under the FCE LTER Program (Grant \#9910514) and by the South Florida Water Management District (Contracts \#C-10244 and C-15397). Yang, C. thanks the Chemistry Department for a Teaching Assistantship. This is contribution \#291 of the Southeast Environmental Research Center at Florida International University.

\section{References}

Alberts, J. J., M. Takacs \& J. Schalles, 2004. Ultraviolet-visible and fluorescence spectral evidence of natural organic matter (NOM) changes along an estuarine salinity gradient. Estuaries 27: 296-310.

Battin, T. J., 1998. Dissolved organic matter and its optical properties in a blackwater tributary of the upper Orinoco river, Venezuela. Organic Geochemistry 28: 561-569.

Blough, N. V. \& R. D. Vecchio, 2002. Chromophoric DOM in the coastal environment. In Hansell, D. A. \& C. A. Carlson (eds), Biogeochemistry of Marine Dissolved Organic Matter. Academic Press, California, 509-546.

Boyer, J. N., J. W. Fourqurean \& R. D. Jones, 1997. Spatial characterization of Water Quality in Florida Bay and Whitewater y Multivariate Analyses: zones of similar influence. Estuaries 20: 743-758.

Boyer, J. N., J. W. Fourqurean \& R. D. Jones, 1999. Seasonal and long-term trends in the water quality of Florida Bay (1989-1997). Estuaries 22: 417-430.

Boyer, J. N., 2006. Shifting N and P limitation along a northsouth gradient of mangrove estuaries in South Florida. Hydrobiologia 569: 167-177.

Bronk, D. A., 2002. Dynamics of DON. In Hansell, D. A. \& C. A. Carlson (eds), Biogeochemistry of Marine Dissolved Organic Matter. Academic Press, California, 153-247.

Caraco, N. F. \& J. J. Cole, 2003. The importance of organic nitrogen production in aquatic systems: A landscape perspective. In Findlay, S. E. G. \& R. L. Sinsabaugh (eds), Aquatic Ecosystems: Interactivity of Dissolved Organic Matter. Academic Press, California, 263-283.

Cauwet, G., 2002. DOM in the coastal zone. In Hansell, D. A. \& C. A. Carlson (eds), Biogeochemistry of Marine Dissolved Organic Matter. Academic Press, California, 579-609. 
Clark, C. D., J. Jimenez-Morais, G. Jones, E. Zanardi-Lamardo, C. A. Moore \& R. G. Zika, 2002. A time-resolved fluorescence study of dissolved organic matter in a riverine to marine transition zone. Marine Chemistry 78: 121-135.

Dittmar, T., R. J. Lara \& G. Kattner, 2001. River or mangrove? Tracing major organic matter sources in tropical Brazilian coastal waters. Marine Chemistry 73: 253-271.

Donard, O. F. X., M. Lamotte, C. Belin \& M. Ewald, 1989. High-sensitivity fluorescence spectroscopy of Mediterranean waters using a conventional or a pulsed laser excitation source. Marine Chemistry 27: 117-136.

Ferrari, G. M. \& M. Mingazzini, 1995. Synchronous fluorescence-spectra of dissolved organic-matter (Dom) of algal origin in marine coastal waters. Marine Ecology-Progress Series 125: 305-315.

Findlay, S. E. G. \& R. L. Sinsabaugh, 2003. Aquatic Ecosystems: Interactivity of Dissolved Organic Matter. Academic Press, California.

Fourqurean, J. W., A. Willsie, C. D. Rose \& L. M. Rutten, 2001. Spatial and temporal pattern in seagrass community composition and productivity in south Florida. Marine Biology 138: 341-354.

Frankovich, T. A. \& R. D. Jones, 1998. A rapid, precise and sensitive method for the determination of total nitrogen in natural waters. Marine Chemistry 60: 227-234.

Guo, L., P. H. Santschi \& T. S. Bianchi, 1999. Dissolved Organic Matter in Estuaries of the Gulf of Mexico. Wiley, New York.

Hansell, D. A. \& C. A. Carlson, 2002. Biogeochemistry of Marine Dissolved Organic Matter. Academic Press, California.

Hitchcock, G. L., R. F. Chen, G. B. Gardner \& W. J. Wiseman, 2004. A Lagrangian view of fluorescent chromophoric dissolved organic matter distributions in the Mississippi River plume. Marine Chemistry 89: 225-239.

Jaffé, R., J. N. Boyer, X. Lu, N. Maie, C. Yang, N. M. Scully \& S. Mock, 2004. Source characterization of dissolved organic matter in a subtropical mangrove-dominated estuary by fluorescence analysis. Marine Chemistry 84: 195-210.

Jones, D., M. Madden, J. Snyder \& K. Rutchey, 1999. A Vegetation Classification System for South Florida National Parks/Preserves, South Florida Natural Resources Center Technical Report, Everglades National Park, National Park Service. U.S. Department of Interior, Homestead, Florida.

Kowalczuk, P., W. J. Cooper, R. F. Whitehead, M. J. Durako \& W. Sheldon, 2003. Characterization of CDOM in an organic-rich river and surrounding coastal ocean in the South Atlantic Bight. Aquatic Sciences 65: 384 401.

Lee, S. Y., 1995. Mangrove outwelling - a review. Hydrobiologia 295: 203-212.

Lu, X. Q., N. Maie, J. V. Hanna, D. L. Childers \& R. Jaffe, 2003. Molecular characterization of dissolved organic matter in freshwater wetlands of the Florida Everglades. Water Research 37: 2599-2606.
Maie, N., T. Miyoshi, D. L. Childers \& R. Jaffé, 2006. Quantitative and qualitative aspects of dissolved organic carbon leached from plants in an oligotrophic wetland. Biogeochemistry (in press).

Maie N., C.-Y. Yang, T. Miyoshi, K. Parish \& R. Jaffé, 2005. Chemical characteristics of dissolved organic matter in an oligotrophic subtropical wetland/estuarine ecosystem. Limnology and Oceanography 50: 23-35.

McKnight, D. M., E. Hood \& L. Klapper, 2003. Trace organic moieties of dissolved organic material in natural waters. In Findlay, S. E. G. \& R. L. Sinsabaugh (eds), Aquatic Ecosystems: Interactivity of Dissolved Organic Matter. Academic Press, California, 71-96.

McKnight, D. M., E. W. Boyer, P. K. Westerhoff, P. T. Doran, T. Kulbe \& D. T. Andersen, 2001. Spectrofluorometric characterization of dissolved organic matter for indication of precursor organic material and aromaticity. Limnology And Oceanography 46: 38-48.

Nuttle, W. K., J. M. Fourqurean, B. J. Zieman, J. C. Cosby \& M. B. Robblee, 2000. Influence of net freshwater supply on salinity in Florida. Bay/Water Resources Research 36: 1805-1822.

Parlanti, E., K. Worz, L. Geoffroy \& M. Lamotte, 2000. Dissolved organic matter fluorescence spectroscopy as a tool to estimate biological activity in a coastal zone submitted to anthropogenic inputs. Organic Geochemistry 31: 1765-1781.

Sierra, M. M., O. F. X. Donard \& M. Lamotte, 1997. Spectral identification and behaviour of dissolved organic fluorescence material during estuarine mixing processes. Marine Chemistry 58: 51-58.

Sierra, M. M. D., O. F. X. Donard, M. Lamotte, C. Belin M. Ewald, 1994. Fluorescence spectroscopy of Coastal And Marine Waters. Marine Chemistry 47: 127-144.

Stedmon, C. A., S. Markager \& R. Bro, 2003. Tracing dissolved organic matter in aquatic environments using a new approach to fluorescence spectroscopy. Marine Chemistry 82: 239-254.

Yamashita, Y. \& E. Tanoue, 2003. Chemical characterization of protein-like fluorophores in DOM in relation to aromatic amino acids. Marine Chemistry 82: 255-271.

Yamashita, Y. \& E. Tanoue, 2004. In situ production of chromophoric dissolved organic matter in coastal environments. Geophysical Research Letters 31: 14302.

Zanardi-Lamardo, E., C. A. Moore \& R. G. Zika, 2004. Seasonal variation in molecular mass and optical properties of chromophoric dissolved organic material in coastal waters of southwest Florida. Marine Chemistry 89: 37-54.

Zieman, J. C., J. W. Fourqurean \& R. L. Iverson, 1989. Distribution, abundance and productivity of seagrasses and macroalgae in Florida Bay. Bulletin of Marine Science 44: 292-311. 